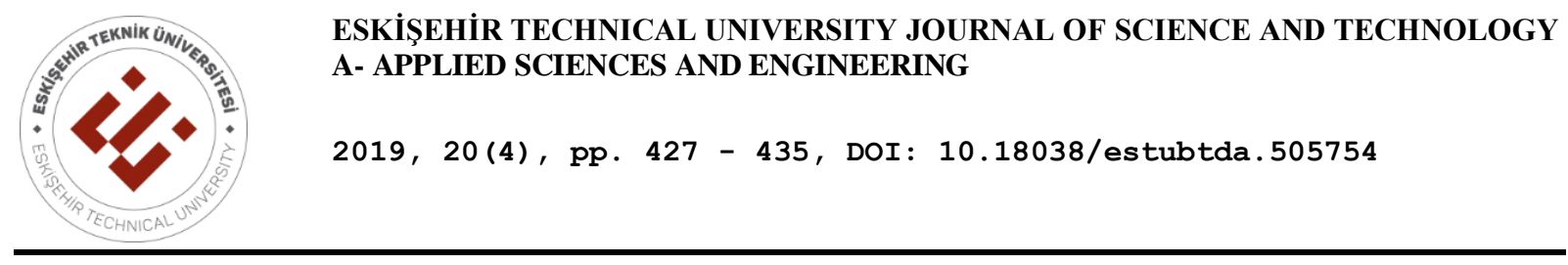

\title{
EFFECT OF GLASS FIBER ADDITION ON THE STRENGTH PROPERTIES AND PORE STRUCTURE OF FLY ASH BASED GEOPOLYMER COMPOSITES
}

\author{
Kasım MERMERDAŞ ${ }^{1, *}$, Esameddin Saeed MULAPEER ${ }^{2}$, Safie Mahdi OLEIWI ${ }^{2,3}$ \\ ${ }^{1}$ Civil Engineering Department, Engineering Faculty, Harran University, Şanlıurfa, Turkey \\ ${ }^{2}$ Civil Engineering Department, Engineering Faculty, Hasan Kalyoncu University, Gaziantep, Turkey \\ ${ }^{3}$ Civil Engineering Department, Engineering Faculty, Diyala University, Baqubah, Iraq
}

\begin{abstract}
This paper presents the results of an experimental program to determine the properties of glass fiber reinforced geopolymer mortar which is a mixture of fly ash, alkaline liquids, fine aggregates, and glass fibers. The effects of inclusion of glass fibers on density, compressive strength, splitting tensile strength, absorption and sorptivity of hardened geopolymer composite (GPC) was studied. Alkaline liquid to fly ash ratio was fixed as 0.33 . $\mathrm{NaOH}$ and $\mathrm{NaSiO}_{3}$ solutions were used as alkaline liquids for activation of fly ash. The alkaline liquid combination ratio of 2.5:1 were used for $\mathrm{Na}_{2} \mathrm{SiO}_{3}: \mathrm{NaOH}$. Glass fiber was added to the mixes in $0.2 \%, 0.4 \%, 0.6 \%, 0.8 \%, 1.0 \%$ and $1.2 \%$ by volume of mortar. A curing regime of 48 hours with $60{ }^{\circ} \mathrm{C}$ temperature was applied. The experimental results indicated that inclusion of the glass fibers resulted in a decrease in the workability, yet, an improvement in compressive strength and splitting tensile strength of fly ash based GPC was obtained by increasing the fiber content. However, the inclusion of glass fiber did not indicate a remarkable change in the water absorption and sorptivity of GPCs.
\end{abstract}

Keywords: Geopolymer, Fly ash, Glass fiber, Strength, Absorption

\section{INTRODUCTION}

Generally, the development of a country depends on its infrastructure, and in most infrastructures, concrete plays a critical role. Hence, we cannot imagine any developments without concrete. Using more concrete in infrastructures means more cement production. As reported by Palomo [1], worldwide annual consumption of concrete is estimated to be about 18 billion tons by the year 2050. Portland cement production processes release a large quantity of carbon dioxide $\left(\mathrm{CO}_{2}\right)$ which significantly affects the greenhouse emissions. Manufacturing of one ton of cement contributes to the production of nearly one ton of $\mathrm{CO}_{2}$. McCaffrey [2] estimated that the ordinary portland cement (OPC) production is rising at the rate of about $3 \%$ annually. On the other hand, the role of $\mathrm{CO}_{2}$ is cognizable for around $65 \%$ of global warming [2]. Since concrete is a widely utilized construction material, and traditionally it is created using OPC as a primary binder material, and due to the increasing order and usage of concrete, the production of OPC will keep increasing, and the emission of further $\mathrm{CO}_{2}$ is inevitable.

Hence, in order to produce environmentally friendly concrete, many materials and methods have been studied to find suitable substitions to be utilized as a partial or complete alternative to portland cement. Davidovits [3] suggested that waste materials or by-product materials such as husk ash, blast furnace slag or fly ash (FA) that contain aluminum (Al) and silicon (Si) can be used with an alkaline to interact as a source material of geological root to produce binder. He named these binders as geopolymers. Therefore, a total replacement of ordinary portland cement can be considered [1]. Therefore, it can be said that geopolymer concrete is a concrete which can be produced without portland cement.

Further consideration of geopolymer is that it is an environmentally friendly material. This is attributed to the fact that the base materials used for geopolymer are either by product or naturally available minerals. Moreover, the properties could better compare with OPC concrete. Sumajouw and Rangan [4] through their study of reinforced geopolymer concrete columns and beams based on low FA content, concluded

\footnotetext{
*Corresponding Author: kasim.mermerdas@harran.edu.tr

Received: 31.12.2018 Published: 30.12.2019
} 
that the produced geopolymer concrete has excellent durable properties. In addition to that, they reported that creep was low, drying shrinkage was very low, the resistance to acid was good and the resistance to sulphate attack was very high. Moreover, another benefit of geopolymer concrete (GC) is the ability to recylcle industrial waste materials that have a disposal problem. For example, FA is a by-product material from combustion coal, particularly in power plants, that are widely available throughout the world.

In order to increase concrete structural integrity, and improve mechanical properties, fibrous materials are added to the concrete. Fibers have been used as reinforcing agents since antiquity, and the idea is not new. Through the history, to improve construction materials, horsehair was added to mortar and mud to make bricks stronger. [5]. The idea of fiber reinforced concrete and composite materials entered the field of interest decades ago and was one of the hot topics [5]. Starting from 1960, many researchers have studied the influence of using various fibers type (synthetic, glass and steel fibers) to strengthen OPC concrete, and tried to observe the effectiveness of fibers on the durability properties. Other researchers such as Choi and Yuan [6] and Ghugal and Deshmukh [7] have investigated the influence of adding glass fibers on the strength properties of conventional OPC concrete. They studied the modified properties of structural concrete by evaluating the results of experimental studies. They reported the influence of alkali-resistant glass fibers on workability, density, of different strengths grade concretes. The fiber content they used varied from 0.5 to $4.5 \%$ by weight of cement. In a recent research by Nematollahi et al. [8], the authors investigated the influence of glass fiber addition on the properties of fresh and hardened FA GC. A solution of $8 \mathrm{M} \mathrm{Na}_{2} \mathrm{SiO}_{3}(71.4 \%)+\mathrm{NaOH}(28.6 \%)$ and a ratio of $\mathrm{SiO}_{2} / \mathrm{Na}_{2} \mathrm{O}$ equals to 2 were utilized to produce GPC. Moreover, they used glass fibers in varying percentages; $0.50 \%, 0.75 \%, 1.00 \%$ and $1.25 \%$ by volume of concrete. The research concluded that with an addition of glass fiber, an increase of flexural strengths, compressive strength, and density along with a decrease in the workability were observed. Another study performed by Vijai et al. [9] on the characteristics of geopolymer concrete reinforced with glass fiber. They conducted split tensile strength and flexural strength tests on glass fiber reinforced geopolymer concrete composite incorporating volume fractions of $0.01 \%, 0.02 \%$ and $0.03 \%$.

Since the beginning of the new millennium, there has been a tendency to produce new alternatives to ordinary portland concrete. As a result of environmental impacts, sustainable options of utilizing industrial wastes to produce useful construction materials have attracted a great interest. This study deals with the development of a FA based geopolymer with enhanced properties. In order to improve the properties of GPC, glass fiber reinforcement was utilized. The investigated properties of FA based glass fiber reinforced geopolymer were compressive and tensile strengths together with absorption characteristics.

\section{EXPERIMENTAL STUDY}

\subsection{Materials}

In this experimental study, the base material was selected as class $\mathrm{F}$ fly ash, and a mix of sodium silicate $\left(\mathrm{Na}_{2} \mathrm{SiO}_{3}\right)$ solution with sodium hydroxide $(\mathrm{NaOH})$ solution as alkaline activator. The specific surface area and the specific gravity of FA are $379 \mathrm{~m}^{2} / \mathrm{kg}$ and 2.25 , respectively. The chemical composition of FA is also given in Table 1. The sodium hydroxide $(\mathrm{NaOH})$ used was in technical grade in flakes form with approximately $3 \mathrm{~mm}$ particle size, a specific gravity of 2.13 and a $\mathrm{pH}$ of 14 . The molar mass used was 40 $\mathrm{g} / \mathrm{mol}$. These information were reported by the supplier, Tekkim Kimya San. Ltd, Turkey.

Table 1. Chemical composition of FA

\begin{tabular}{|c|c|c|c|c|c|c|c|c|}
\hline \multicolumn{2}{|c|}{ Chemical composition (\%) } \\
\hline $\mathrm{CaO}$ & $\mathrm{SiO}_{2}$ & $\mathrm{Al}_{2} \mathrm{O}_{3}$ & $\mathrm{Fe}_{2} \mathrm{O}_{3}$ & $\mathrm{MgO}$ & $\mathrm{SO}_{3}$ & $\mathrm{~K} 2 \mathrm{O}$ & $\mathrm{Na} 2 \mathrm{O}$ & LOI $^{*}$ \\
\hline 2.2 & 57.2 & 24.4 & 7.1 & 2.4 & 0.3 & 3.4 & 0.4 & 1.5 \\
\hline
\end{tabular}

*LOI: Loss on Ignition 
The preparation of sodium hydroxide $(\mathrm{NaOH})$ solution was done by dissolving sodium hydroxide flakes in water. The mass of $\mathrm{NaOH}$ solids in a solution disperse according to the solution concentration expressed in terms of the molar, $\mathrm{M}$. In this research, $\mathrm{NaOH}$ solution with $12 \mathrm{M}(480 \mathrm{~g} / \mathrm{L})$ was used. In order to provide this molarity a volume measured beaker was used. Firstly, $\mathrm{NaOH}$ flakes are added, then water is add until the volume is completed to $1 \mathrm{~L}$. After the stirring process is completed the solution was left to cool down, then the beaker was refilled to $1 \mathrm{~L}$.

Readymade solution of Sodium silicate was obtained from the market. The sodium silicate solution has the chemical composition of $\mathrm{SiO}_{2}=29.4 \%, \mathrm{Na}_{2} \mathrm{O}=14.7 \%$ and water of about $55.9 \%$ by mass. The specific gravity of sodium hydroxide solution was $=1.48 \mathrm{~g} / \mathrm{cc}$ and the viscosity was $=400 \mathrm{cp}$ at $20{ }^{\circ} \mathrm{C}$.

The aggregate used in this study was provided from a local river quarry (river sand). Only fine aggregate $(0-4 \mathrm{~mm})$ was used. The aggregate was stored in laboratory conditions. The specific gravity of the aggregate, as obtained according to ASTM C128, was 2.64.

In order to improve the flow of the mortar, a polycarboxylate ether type superplasticizer (SP), in a solution form with a specific gravity of 1.07 , was used with a ratio of $6 \%$ of fly ash weight in all mixtures. The amount of superplasticizer was determined through initial trials to obtain suitable consistency for workability.

The mixing stage has notable effects on the production of GPC. Inappropriately mixed mortar may cause failures such as not hardening, flash setting or both, which causes inapplicability.

In order to avoid these drawbacks, the selection of mixtures ingredient was made based on the previous researches that were summarized in previous works and the results of some trial mixtures in the preliminary study. The selection steps are summarized as following:

- FA was used as a base material. Two series of mixtures based on fly ash ratio of $600 \mathrm{~kg} / \mathrm{m}^{3}$ and $700 \mathrm{~kg} / \mathrm{m}^{3}$ were prepared.

- A mixture of sodium hydroxide $(\mathrm{NaOH})$ solution and sodium silicate solution $\left(\mathrm{Na}_{2} \mathrm{SiO}_{3}\right)$ was used as alkaline liquid by a ratio of 1 to 2.5 respectively. The molarity of sodium hydroxide was $12 \mathrm{M}$.

- The ratio of alkaline solution to FA was 1:2 by mass.

- $50 \%$ of the volume of the mixture was aggregate with size of 0-4 mm.

- Super plasticizer was used with a ratio of $6 \%$ by mass of FA.

- Glass fiber chopped as $6 \mathrm{~mm}$ long was added with a range of between 0.2 to 1.2 of the total volume of the mixture.

- A total of 12 mixtures was obtained.

The mix proportions of the geopolymer mortars (GPC) are given in Table 2 and Table 3.

Table 2. Mix proportions for GPCs with $600 \mathrm{~kg} / \mathrm{m}^{3}$ binder

\begin{tabular}{|c|c|c|c|c|c|c|c|c|}
\hline \multirow{2}{*}{ \# } & \multirow{2}{*}{ Mix ID } & \multirow{2}{*}{$\begin{array}{l}\text { Fly ash } \\
\text { (FA) } \\
{\left[\mathrm{kg} / \mathrm{m}^{3}\right]}\end{array}$} & \multirow{2}{*}{$\begin{array}{c}\text { Aggregates } \\
\text { (fine) } \\
{\left[\mathrm{kg} / \mathrm{m}^{3}\right]}\end{array}$} & \multirow{2}{*}{$\begin{array}{l}\mathrm{NaOH} \\
\text { solution } \\
{\left[\mathrm{kg} / \mathrm{m}^{3}\right]}\end{array}$} & \multirow{2}{*}{$\begin{array}{l}\mathrm{Na}_{2} \mathrm{SiO}_{3} \\
\text { solution } \\
{\left[\mathrm{kg} / \mathrm{m}^{3}\right]}\end{array}$} & \multicolumn{2}{|c|}{ Glass fiber } & \multirow{2}{*}{$\begin{array}{c}\text { Superplasticizer } \\
\text { [\%] of FA }\end{array}$} \\
\hline & & & & & & [\%] of volume & {$\left[\mathrm{kg} / \mathrm{m}^{3}\right]$} & \\
\hline 1 & GPM $0.2 \%$ & 600 & 1278.2 & 85.7 & 214.2 & 0.2 & 5.2 & 6 \\
\hline 2 & GPM $0.4 \%$ & 600 & 1273.0 & 85.7 & 214.2 & 0.4 & 10.4 & 6 \\
\hline 3 & GPM $0.6 \%$ & 600 & 1267.6 & 85.7 & 214.2 & 0.6 & 15.6 & 6 \\
\hline 4 & GPM $0.8 \%$ & 600 & 1262.3 & 85.7 & 214.2 & 0.8 & 20.8 & 6 \\
\hline 5 & GPM $1.0 \%$ & 600 & 1257.0 & 85.7 & 214.2 & 1 & 26 & 6 \\
\hline 6 & GPM $1.2 \%$ & 600 & 1251.8 & 85.7 & 214.2 & 1.2 & 31.2 & 6 \\
\hline
\end{tabular}


Mermerdaş et al. / Eskişehir Tech. Univ. J. of Sci. and Technology A - Appl. Sci. and Eng. 20 (4) - 2019

Table 3. Mix proportions for GPCs with $700 \mathrm{~kg} / \mathrm{m}^{3}$ binder

\begin{tabular}{lcccccccc}
\hline \# & Mix ID & $\begin{array}{c}\text { Fly ash } \\
(\mathrm{FA})\end{array}$ & $\begin{array}{c}\text { Aggregates } \\
\text { (fine) }\end{array}$ & $\begin{array}{c}\mathrm{NaOH} \\
\text { solution }\end{array}$ & $\begin{array}{c}\mathrm{Na}_{2} \mathrm{SiO}_{3} \\
\text { solution }\end{array}$ & Glass fiber & Superplasticizer \\
& & {$\left[\mathrm{kg} / \mathrm{m}^{3}\right]$} & {$\left[\mathrm{kg} / \mathrm{m}^{3}\right]$} & {$\left[\mathrm{kg} / \mathrm{m}^{3}\right]$} & {$\left[\mathrm{kg} / \mathrm{m}^{3}\right]$} & {$[\%]$ of volume } & {$\left[\mathrm{kg} / \mathrm{m}^{3}\right]$} & {$[\%]$ of $\mathrm{FA}$} \\
\hline 1 & GPM 0.2\% & 700 & 1052.1 & 99.96 & 249.9 & 0.2 & 5.2 & 6 \\
2 & GPM 0.4\% & 700 & 1046.8 & 99.96 & 249.9 & 0.4 & 10.4 & 6 \\
3 & GPM 0.6\% & 700 & 1041.5 & 99.96 & 249.9 & 0.6 & 15.6 & 6 \\
4 & GPM 0.8\% & 700 & 1036.2 & 99.96 & 249.9 & 0.8 & 20.8 & 6 \\
5 & GPM 1.0\% & 700 & 1030.9 & 99.96 & 249.9 & 1.0 & 26.0 & 6 \\
6 & GPM 1.2\% & 700 & 1025.7 & 99.96 & 249.9 & 1.2 & 31.2 & 6 \\
\hline
\end{tabular}

\subsection{Casting and Curing}

Firstly, the molds with dimensions of $50 \times 50 \times 50 \mathrm{~mm}^{3}$ were prepared and lubricated to prevent adhesion of geopolymer to the molds. The second step was filling the first half of molds with prepared mix by 25 stroke per layer, then a mechanical vibration for 25 seconds on vibration table was done to reduce the air bubbles inside the mortar. The same procedure was done for the next layer. After that, the top of molds was leveled to get a uniform shape and extra materials were removed. Before curing process, the molds were covered by heat resistant film to prevent moisture loss during high temperature curing. Then, curing processes were started.

From the most of the previous researches, it was found out that for the rapid and effective strength development of geopolymer, temperature curing is suggested. For that, heat curing was used by using electrical oven with constant temperature at $60{ }^{\circ} \mathrm{C}$ for $48 \mathrm{hrs}$.

\subsection{Testing Procedures}

In order to measure the fresh unit weight of geopolymer mortar according to ASTM C 138, a digital scale was used for weighing the molds when empty and after casting. A calipers was used to check the dimensions of molds.

The compressive strength test of GPC cube samples made according to ASTM C109, was performed in a $3000 \mathrm{kN}$ capacity universal testing machine according to ASTM C39 (2012). The test was performed on the specimens at the age of $48 \mathrm{hrs}$, with a loading rate of $0.5 \mathrm{kN} / \mathrm{sec}$. The compressive strength was calculated from the average of three samples.

The splitting tensile test for GPC specimens was done by $3000 \mathrm{kN}$ capacity hydraulic testing machine on 50x50x50 mm cubes, the test was executed on the specimens at the age of $48 \mathrm{hrs}$. with the loading rate of $0.1 \mathrm{kN} / \mathrm{sec}$. The splitting tensile strength was calculated from the average of three samples at each age test.

To determine the water absorption of GPCs three cubes were casted with dimensions of $50 \times 50 \times 50 \mathrm{~mm}^{3}$ with similar method of curing. The test was done on the specimen at age of 7 days. First, the dimensions and density were measured, and the specimen were dried in oven at a temperature of $100{ }^{\circ} \mathrm{C}$ for $24 \mathrm{hrs}$. Then the specimens were immersed for $24 \mathrm{hrs}$. in water, then the second weight as saturated surface dry weight was measured. Finally, the calculation of water absorption amount of specimens as the percentage increase in weight, was done by Equation 1.

$$
W A=\frac{W_{2}-W_{1}}{W_{1}} \times 100
$$


Where $W A$ is the water absoption as percentage, $W_{l}$ is weight of dry specimen in grams and $W_{2}$ is weight of saturated surface dry specimen in grams.

The sorptivity test was done to obtain the ratio of water drawn into the pores of geopolymer mortar. For sorptivity test, three cubes were prepared with dimensions of $50 \times 50 \times 50 \mathrm{~mm}^{3}$ with similar method of curing. The test was done on the specimens at age of 7 days. The specimens were oven dried at $100{ }^{\circ} \mathrm{C}$ for 24 hours, then they were taken out of the oven and coated on the sides only with silicone sealing in order to ensure that water can ingress only from the bottom of the specimens. After that, the mortar specimens were immersed in water, where the water was kept at a level not more than 3-5 $\mathrm{mm}$ above the base of specimen. The increases in the mass of the specimen at 1, 4, 9, 16, 25, 36, 49 and 64 minutes were measured. Sorptivity index can be determined by the following empirical relation (Eq 2)

$$
I=S \times \sqrt{t}
$$

Where $I$ is volume of the capillary absorbed water per unit area $\left(\mathrm{mm}^{3} / \mathrm{mm}^{2}\right), S$ is sorptivity index $\left(\mathrm{mm}^{3} / \mathrm{mm}^{2} / \mathrm{min}^{0.5}\right), t$ is time (minutes)

\section{TEST RESULTS AND DISCUSSIONS}

Compressive strength can be considered as a good indicator of the durability. Therefore, compressive strength is considered one of the most important features of geopolymer mortar. Figure 1 shows the compressive strength tests results.

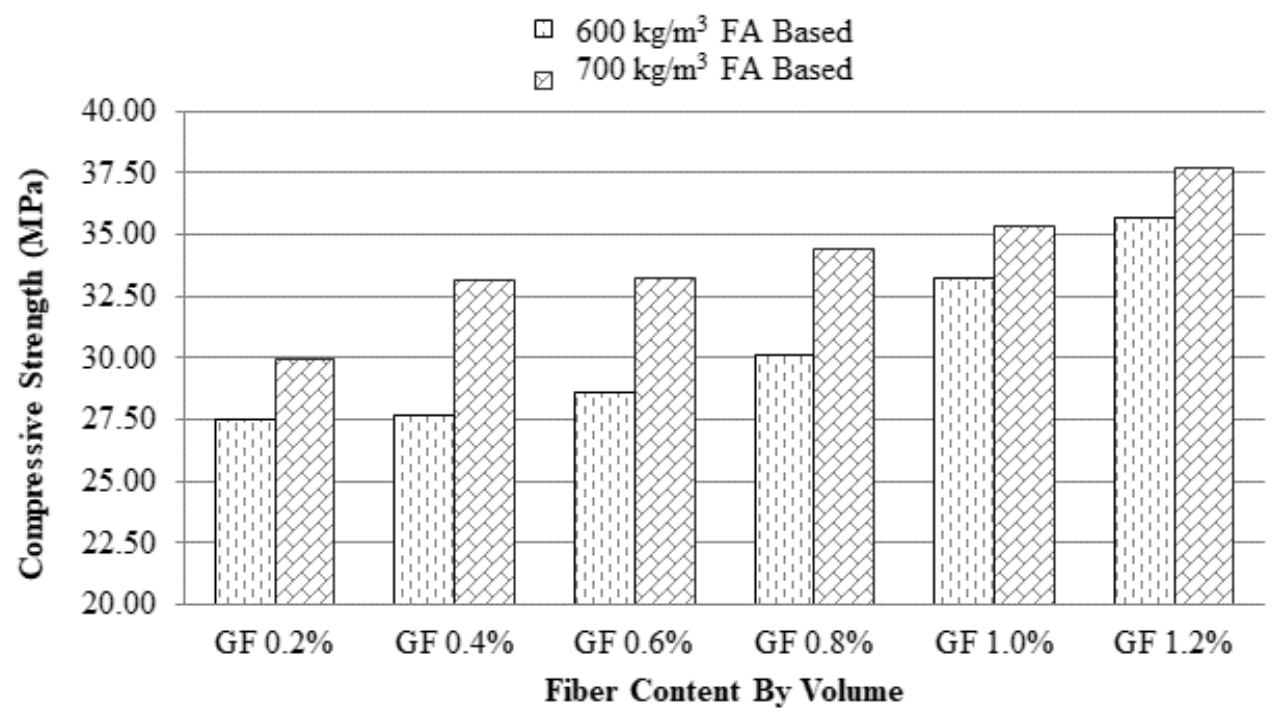

Figure 1. Compressive strength results

The average compressive strength was obtained as $30.48 \mathrm{MPa}$ for series 1 , which is $600 \mathrm{~kg} / \mathrm{m}^{3} \mathrm{FA}$ based, and $33.97 \mathrm{MPa}$ for series 2, which is $700 \mathrm{~kg} / \mathrm{m}^{3} \mathrm{FA}$ based. Moreover, as shown in Figure 1, the compressive strength increased with increasing the fiber glass content from $0.2 \%$ to $1.2 \%$, with a ratio of about $30 \%$ for series 1 , and $26 \%$ for series 2 . This can be caused by the effect of glass fibers that controls the cracks during the loading processes and improve the strength. Additionally, it was observed that the compressive strength was increased by $11.5 \%$ when the base material FA was increased from $600 \mathrm{~kg} / \mathrm{m}^{3}$ to $700 \mathrm{~kg} / \mathrm{m}^{3}$. 
The splitting tensile strength test results are shown in Figure 2. The average splitting tensile strengths are 4.16 MPa for series1, and 4.14 MPa for series 2.

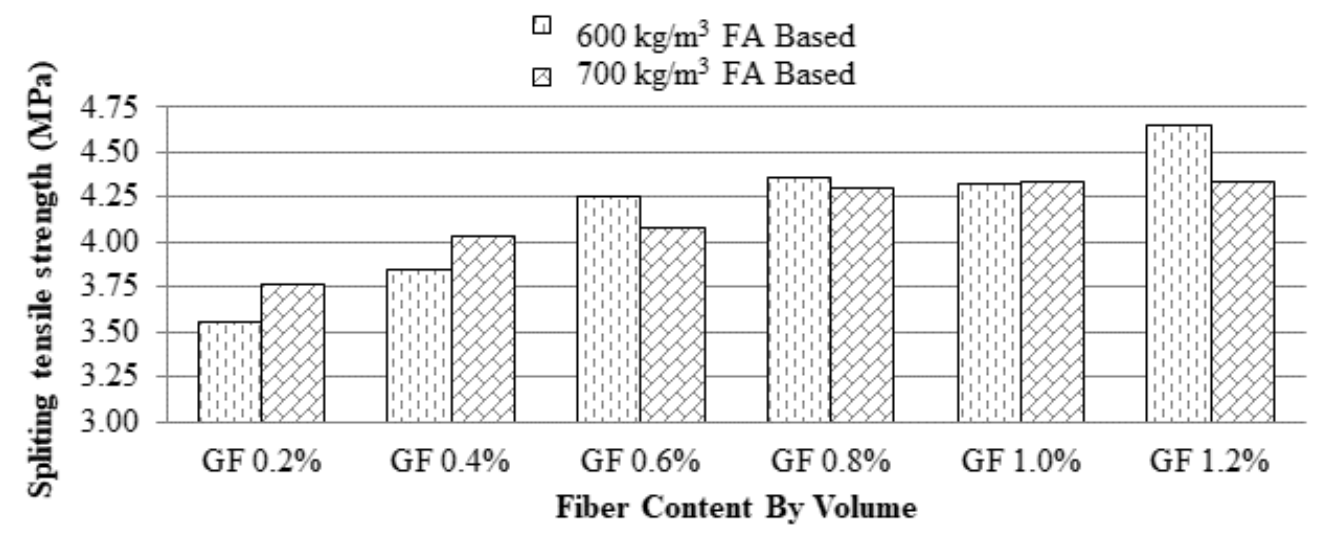

Figure 2. Spliting tensile strength

According to the results, it was observed that the splitting tensile was increased by increasing glass fiber from $0.2 \%$ to $1.2 \%$. The highest increase was observed to be $31 \%$. Increasing the base material from $600 \mathrm{~kg} / \mathrm{m}^{3}$ to $700 \mathrm{~kg} / \mathrm{m}^{3}$ had no clear effect or a specific trend over this property. Figure 3 shows the correlation between the compressive strength and the splitting tensile strength. The first one increased proportionally with the increase of the latter. The highest coefficient determination $\left(\mathrm{R}^{2}\right)$ value of 0.94 was obtained through a polynomial curve.

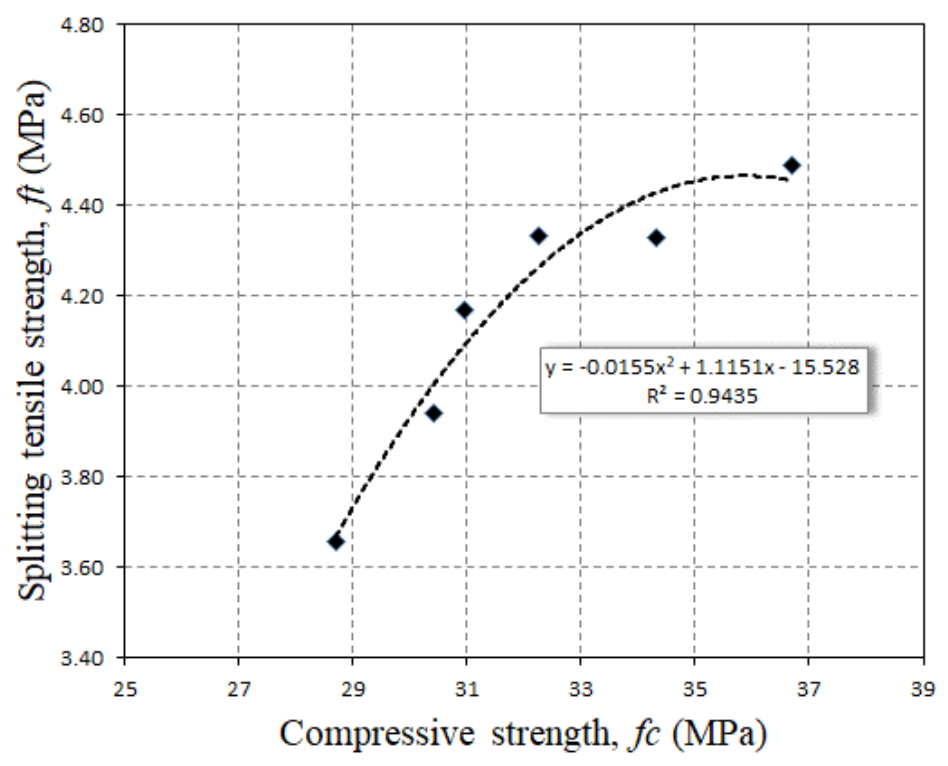

Figure 3. Correlation between compressive strength and splitting tensile strength

Generally, glass fiber improves the mechanical characteristics of geopolymer mortar or geopolymer concrete, as well as in ordinary concrete. Kizilkanat et al [10] concluded that the compressive strength and splitting tensile strength increased by increasing the glass fiber content. Nematollahi et al [8] also observed that the compressive strength and flexural strength of geopolymer concrete improved by using glass fiber. In addition to that, absorption should be considered when investigating durability, because it affects the durability of concrete. Figure 4 shows the results of water absorption. 


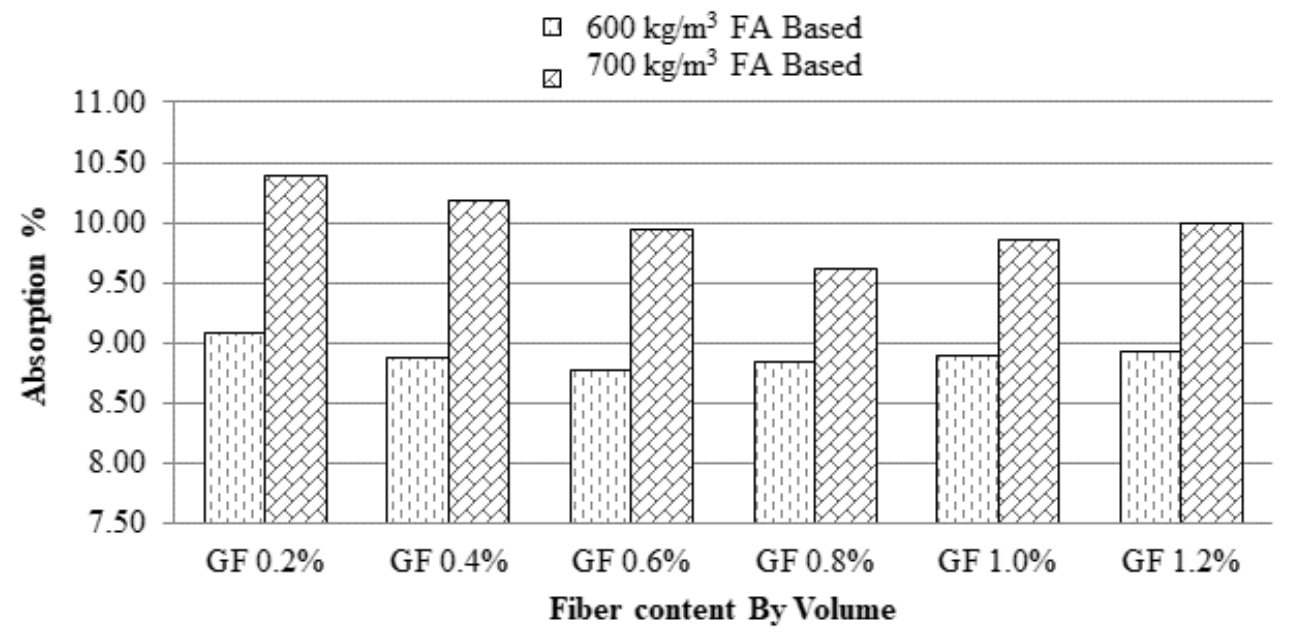

Figure 4. Water absorption

Absorption of ordinary concrete or geopolymer concrete can be related to the number of pores inside the concrete. According to the results, the average water absorption was about $8.90 \%$ for series 1 and $10.00 \%$ for series 2 . Based on the results of water absorption, there is insignificant change in the results by changing the amount of glass fiber content. For both series, the slight change occurs when the fiber content changes. This can be related to change in workability or compactability of the mixture when fibers are added. In other words, the highest compactability obtained for a GF content of $0.6 \%$ and $0.8 \%$ for series 1 and series 2 respectively. This means that these two fiber ratios may be considered as the optimum ones. Because, for the mixtures having fiber proportions less than $0.6 \%$, effective mechanical performance could not been observed. However, for the mixes having the fiber ratio of higher than $0.8 \%$, excessive amount of water is required which induces extra voids after geopolymerization and evaporation. Moreover, increasing the amount of geopolymer binder resulted in more porous structure which was indicated by absorption results. This can also be related to reduction in workability that occurs when a larger portion of fine particles (of FA) are introduced into the matrix. Although, the amount of SP was increased with the increase of FA, it has no effect on improving the workability, since it is already exceeding the maximum amount needed for such mixtures.

Sorptivity measures the capacity of material to absorb water by capillary action. Figure 5 shows the sorptivity results of FA based geopolymer mortars modified with glass fiber.

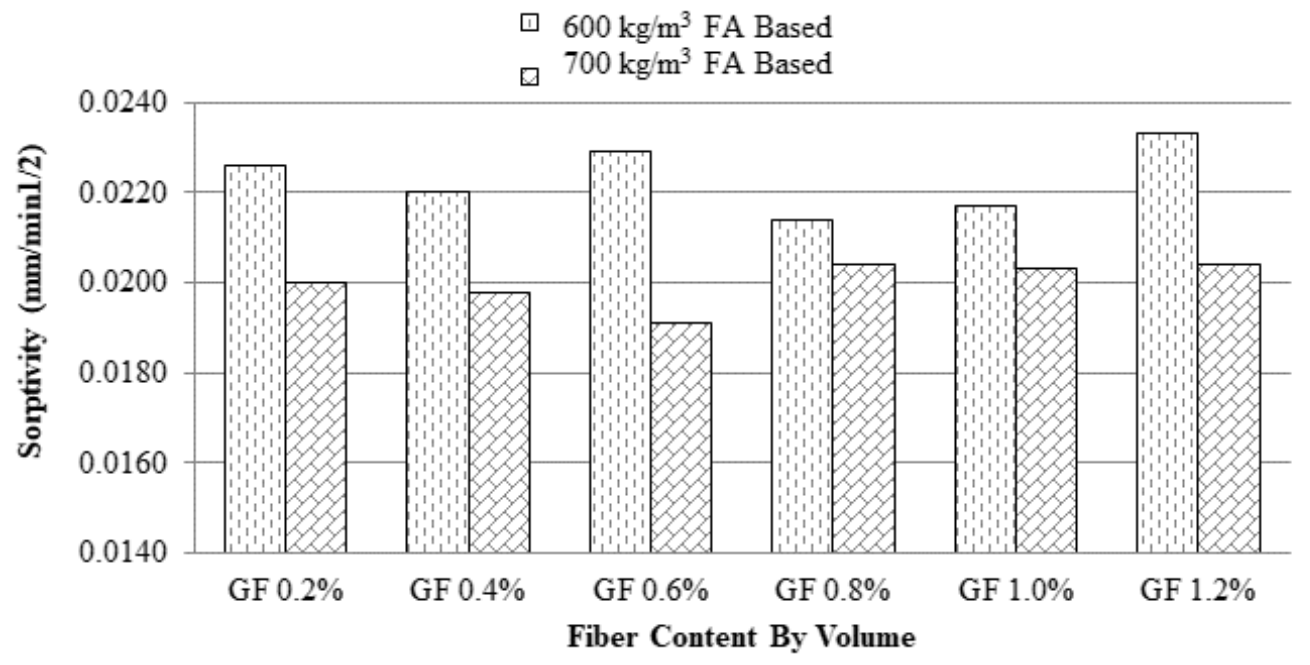

Figure 5. Sorptivity values 
Generally, sorptivity results are very low compared to the sorptivity of ordinary portland cement mortar (up to $0.6 \mathrm{~mm} / \mathrm{min}^{1 / 2}$ given in [11]). For example, in series 1 , the average of sorptivity indices is 0.0223 $\mathrm{m} / \mathrm{min}^{1 / 2}$, while for series 2 , the average is $0.0200 \mathrm{~mm} / \mathrm{min}^{1 / 2}$. According to the results, it was observed that GPCs have low absorption. Moreover, based on the absorption results, there is insignificant change in the results due to changing the amount of glass fiber content. This may due to the fact that the glass fiber distorts the internal structure of geopolymer mortar. In other words the capillary structure of the geopolymer is affected from micro glass fibers. Accordingly, the above findings can be summarized as, although there is no difference in porosity, the capillarity seemed to be affected from glass fiber addition.

According to the results, moderate absorption with low sorptivity was observed. Absorption amount is due to the amount of porosity inside mortar, but it does not indicate that the mortars have high capillarity. This may be related to the denser structure of geopolymer matrix.

\section{CONCLUSION}

According to the experimental test results, the following conclusions are drawn:

- FA based geopolymer binder has the potential to completely eliminate cement in concrete and helps to prevent global warming and to use waste material (FA) effectively. However, more advanced studies are required to be conducted to prove that geopolymer is better than concrete in all the fields and tests.

- FA based geopolymer concrete can be used in areas where rapid final strength achievement is needed as it gains its final strength in about (24-48 hrs.) curing. However, this can be applied for precast elements. For the site applications, further investigations are needed for ambient curing regime.

- Thanks to early strength development due to accelerated curing regime, glass fiber reinforced FA based geopolymer composite productions can be offered to manufacture precast structural elements in construction industry.

- The compressive strength of glass fiber reinforced FA based geopolymer increased about $28 \%$ by increasing the amount of glass fiber content from $0.2 \%$ to $1.20 \%$. The splitting tensile strength increased about $31 \%$ by increasing the amount of glass content from $0.2 \%$ to $1.20 \%$.

- As a result of the experimental study on the absorption properties of geopolymer mortar monitored herein, it can be inferred that this material can be considered as a resistant construction material against aggressive environments owing to its very low capillary absorption property.

\section{REFERENCES}

[1] Palomo A, Blanco MT, Grutzeck M W. Alkali-activated fly ashes, a cement for the future, Cement and Concrete Research, 1999; 29: 1323-1329.

[2] McCaffrey R. Climate change and the cement industry, Global Cement and Lime Magazine Environmental Special Issue 2002, 15-19.

[3] Davidovits J. Mineral polymers and methods of making them, United States Patent, 1988; 4: 349386.

[4] Sumajouw MDJ, Rangan BV. Low-Calcium Fly-Ash based geopolymer concrete: reinforced beams and columns, Research Report GC3, Faculty of Engineering, Curtin University of Technology, Perth, 2006

[5] Mehta PK, Paulo Monteiro JM. Concrete Microstructure, Properties, and Materials, 3rd edition 2006 
Mermerdaş et al. / Eskişehir Tech. Univ. J. of Sci. and Technology A - Appl. Sci. and Eng. 20 (4) - 2019

[6] Choi Y, Yuan, RL. Experimental relationship between splitting tensile strength and compressive strength of GFRC and PFRC. Cement and Concrete Research, 2005; 35(8): 1587-1591.

[7] Ghugal YM, Deshmukh SB. Performance of alkali-resistant glass fiber reinforced concrete. Journal of reinforced plastics and composites, 2006; 25(6): 617-630.

[8] Nematollahi B, Sanjayan J, Chai JXH, Lu TM,. Properties of Fresh and Hardened Glass Fiber Reinforced Fly Ash Based Geopolymer Concrete. Key Engineering Materials. 2014; 594-595

[9] Vijai K, Kumutha R, Vishnuram, BG.. Properties of glass fibre reinforced geopolymer concrete composites. Asian journal of civil engineering Building and housing, 2012; 13, 511-520.

[10] Kizilkanat AB, Kabay N, Akyüncü V, Chowdhury S, Akça AH. Mechanical properties and fracture behavior of basalt and glass fiber reinforced concrete, an experimental study, Construction and Building Materials, 2015; 100:218-224.

[11] Güneyisi E, Gesoğlu M, Özturan T, Mermerdaş K, Özbay E. Properties of mortars with natural pozzolana and limestone based blended cements. ACI Materials Journal, 2011; 108, 493-500. 